Immediately above Tardenois I is Tardenois II in Level 6. Here appear the true trapeze, half-moons, the small implements with transverse cutting-edge and the first indications in technique of the approaching Neolithic, to which the next level belongs.

Tardenois III, the first neolithic phase, appears in Level 7, in which there are several hut-sites, clearly of the same age, with an abundance of implements. The technique is essentially the same as that of the two preceding Tardenois industries, but the cores and scrapers are larger and the large burins, planes and picks, and other forms characteristic of a neolithic industry appear. There are no polished implements. Pottery, absent in the lower levels, is abundant. The forms cannot be reconstructed, owing to the fragmentary condition of the finds; but the ornament is either impressed with the finger, in relief, or incised in horizontal lines and bands, or in the incised ornament, in oblique lines. It resembles pottery with impressed or incised ornament from Spain, France (Gard, Aude, Drôme, Lozère), Swiss lake dwellings and the beginnings of æneolithic and bronze in Belgium. Art is represented by an important human mask in calcareous stone, resembling the figures of the menhirs, and a phallic bisexual object. The culture appears to be advanced neolithic, bordering on the æneolithic.

Le Roc Allan. Here on the second site no less than nineteen levels have been distinguished, extending from Magdalenian to the modern surface. Except in the Azilian and the Sauveterrian the deposits are thin. Impressions of leaves from Tardenois levels have been identified and indicate a vegetation in mesolithic times comparable to that of to-dayHedera, Ruscus, Ilex, Populus, Ulmus, Quercus, Corylus, Acer. The industries of the various levels follow those of Le Martinet sufficiently closely to call for no special comment here.

The results of these excavations, and especially the stratigraphy of mesolithic industries, constitute a contribution of the first importance to prehistoric science. As M. Coulonges points out, not only does it throw light on the development of the Tardenoisian industry and on its differentiation and chronology in relation to other cultures; but it also makes possible for the first time the characterisation of a new industry, often confused with the Tardenoisian, namely, the Sauveterrian. The Tardenoisian itself, which has often been regarded, in the absence of stratigraphic evidence, as merely a form or type, must now be regarded as a widely distributed and distinct culture, not entirely microlithic, but one in which the trapezoidal implement, if characteristic, is associated with forms which conform to the normal in size. From this must be distinguished the Sauveterrian, an industry with which triangular microliths are associated, and derived from the Upper Palæo. lithic.

In Tardenois I two types are distinguished, a coastal which appears at Mugem in Portugal and in the Morbihan, with widely spread affinities, of which the racial type is seen in the short dolichocephals of Mugem, and a continental, which appears at Le Martinet and in the Tardenois of Central Germany, of which the racial type is the skeleton of Cuzoul de Gramat.

Since the distinction to be drawn between Sauve. terrian and Tardenoisian has been pointed out, its existence has been notified from a large number of stations generally distributed over France. The racial type is the man of Roc-du-Barbeau (Dordogne).

The classification which M. Coulonges now proposes is as follows.

Final Paloeolithic: (1) Upper Magdalenian; Proto-Azilian.

Mesolithic: (1) Azilian, subdivided into a Perigordian facies and a Pyrenean facies; (2) Sauve. terrian, subdivided into Extended Aurignacian, Extended Magdalenian (rare), and Final Azilian; (3) Tardenois I, subdivided into coastal and con. tinental ; (4) Tardenois II.

Neolithic: Tardenois III and the civilisations of the polished axe.

\title{
Elements beyond Uranium
}

$\mathrm{T}$ $\mathrm{HE}$ possibility of producing elements with atomic numbers greater than 92 was discussed in 1934 by Fermi and his colleagues, who found that nearly all the elements undergo some transformation when bombarded with neutrons, and it was claimed that, among the products derived from uranium in this process, two at least, with half-life periods of 13 minutes and 90-100 minutes, must lie in the unknown range beyond uranium.

In view of the fact that this claim was challenged by von Grosse and Agruss (Nature, 134, 773, November 17,1934$)$, who declared that the 13minute radio-element must be an isotope of protactinium, it is interesting to read in the April issue of the Berichte der deutschen chemischen Gesellschaft that Profs. Otto Hahn and Luise Meitner and Herr F. Strassmann have found substantial support for Fermi's contention by devising a satisfactory chemical method of separating the products of bombardment of uranium from known elements and to some extent from one another. Thus the so-called 13-minute and 100-minute products are both precipitated by hydrogen sulphide from strong acid solutions containing either platinum or rhenium as carriers, whereas elements Nos. 90-92 all remain dissolved. Moreover, they do not share with protactinium (No. 91) the characteristic property of co-precipitation with zirconium phosphate. Thus it is concluded that they are trans-uranic elements. That they are not themselves isotopes follows from the fact that they can be separated by means of sodium hydroxide.

Further examination has shown that the half-life periods have been incorrectly estimated, and that the longer-lived product is a mixture of homologues of the platinum group (Nos. 94-96). These can all be separated from eka-rhenium (No. 93) by precipitation in acid solution by platinum foil. Alto. gether five or six trans-uranic radio-elements have been detected, namely, two isotopes of eka-rhenium, two of eka-osmium, one of eka-iridium and perhaps one of eka-platinum, the corresponding half-life periods being 16 minutes, $2 \cdot 2$ minutes, 12 hours, 59 minutes, 3 days and about 3 hours. The first and third of these are produced only by 'fast' neutrons, 
the others more readily by neutrons which have been delayed by passage through thick layers of water, paraffin and other hydrides.

The mechanism of the transformations is discussed at some length. Bombardment of an atom by a neutron will produce an element of lower atomic number whenever an $\alpha$-particle or a proton is eliminated, but this effect will be counteracted or even reversed when the unstable product emits sufficient $\beta$-radiation. On the other hand, an initial decrease in atomic number may be avoided, either by the expulsion of a second neutron along with the bombarding neutron, or by the mere absorption of the latter without nuclear disintegration. These effects are produced by 'fast' and 'slow' neutrons respectively, and in both cases the initial products become stabilised by the emission of $\beta$-rays, with consequent increase in atomic number.

A plate showing three photographic exposures by the Wilson method in a magnetic field is given as evidence of the $\beta$-radiation of trans-uranic elements.

\section{Educational Topics and Events}

Belfast.-The Senate has decided to confer the honorary degree of D.Sc. on Prof. T. H. Milroy, emeritus professor of physiology, and Prof. W. B. Morton, emeritus professor of physics.

Cambridge.-It is proposed by the Buildings Syndicate that a site for a new School of Anatomy be assigned on the Downing Street site in the court surrounded by the Schools of Agriculture, Pathology and Biochemistry and the Molteno Institute.

D. R. Pye, of Trinity College, has been approved for the degree of Sc.D., and Miss M. J. Stephenson, of Newnham College, for the title of the degree of Sc.D.

Dr. E. A. Moelwyn-Hughes, of Corpus Christi College, has been admitted by incorporation to the degree of Ph.D.

Mr. F. T. Brookes, fellow of Emmanuel College and University reader in mycology, has been appointed to the professorship of botany vacant by the resignation of Prof. A. C. Seward.

The Cambridge Philosophical Society is holding an exhibition of historic scientific apparatus in the Old Schools on June 8-23. The exhibition will be opened by Lord Rutherford in the Regent House of the Old Schools on June 8 at 9 p.m.

LIVERPOoL.-The University is to confer the honorary degree of Doctor of Laws upon Mr. Harold Cohen in special recognition of his munificent gift of $£ 100,000$ for the erection of a new Library, and for his previous gifts to the endowment fund of the library, and to the Students' Union.

London.-The University's great scheme for building on its Bloomsbury site to the north of the British Museum is in process of realisation. The 'senate-house block', comprising accommodation for the meetings of the Court, the Senate and its various committees, a conference room, small hall and the administrative offices, is, says the Principal's Report for 1935-36, nearing completion, and it is hoped that the first part of the move from the Imperial Institute building in South Kensington will be achieved during the coming long vacation. So, exactly a hundred years after its foundation by Royal Charter in 1836 , the University will occupy a home of its own. From its foundation until 1900 , the functions of the University were almost entirely restricted to those of examination, and examination statistics still figure prominently in its annual reports. In the past year, candidates numbered 44,274 , as compared with 42,822 in 1934 and 16,906 in 1919 . The number of students reading in colleges of, or affiliated to, the University was 13,364. External students registered as preparing for the University's external examinations exceeded 12,000, of whom 6,000 were preparing for various intermediate examinations and 4,000 for degree examinations. Among the numerous benefactions mentioned in the report, a significant item is Sir Montague Burton's gift of $£ 500$ a year for the partial endowment of the chair of international relations at the London School of Economics. Seeing that a large proportion of the students in attendance at the School are residents of countries outside the British Isles (37 per cent of the 911 full-time students in 1934-35 were from abroad) it is obviously desirable to maintain and, if possible, enhance the prestige of this chair.

THE Trustees of the Garton Foundation have awarded the Garton Foundation studentship in the social sciences for 1936 to Mr. Harold Barger of the University of London (University College). The studentship, founded in 1928 by the late Sir Richard Garton, is intended to assist students of exceptional capacity to devote themselves for a year or more to the study of social or economic problems of fundamental importance. It is open to British subjects, and is of the annual value of $£ 400$ and is offered every second year. Mr. Barger proposes to study the economic fluctuations in the United States since the Great War.

The Committee of Award of the Commonwealth Fund fellowships has made the following appointments, among others, to fellowships tenable by British graduates in American universities for the two years beginning September 1936. Gordon Bowen (Liverpool and Glasgow), to the University of California, in geography ; P. M. Butler (Cambridge), to Columbia University, in zoology ; H. R. X. D'Aeth (Cambridge), to Harvard University, in botany; J. C. Dykes (Cambridge), to the California Institute of Technology, in engineering; R. G. Flood (Manchester), to the University of Chicago, in economics ; Dr. G. C. Hampson (Oxford), to the California Institute of Technology, in chemistry; W. M. Honeyman (St. Andrews), to Columbia University, in medicine; J. C. Hornel (Edinburgh), to the University of California, in chemistry; Dr. M. S. Jones (Edinburgh), to the University of Pennsylvania, in medicine; Dr. W. B. Mann (Imperial College of Science and Technology, London), to the University of California, in physics ; F. H. Merrill (Liverpool), to the Massachusetts Institute of Technology, in engineering; A. L. Percival (Cam. bridge), to the Massachusetts Institute of Technology, in engineering; Dr. Donald Purdie (Cambridge), to Stanford University, in chemistry; H. D. Springall (Oxford), to the California Institute of Technology, in chemistry ; Dr. E. G. Taylor (University College, Swansea), to Brown University, in chemistry. The following have been appointed to fellowships tenable by candidates from the British Dominions: I. P. 